JOURNAL OF

APPLIED

CRYSTALLOGRAPHY

ISSN 1600-5767

Received 25 October 2021

Accepted 3 November 2021

Keywords: small-angle scattering; SAS; triennial SAS conferences; International Union of Crystallography; IUCr; Guinier Prize; standards

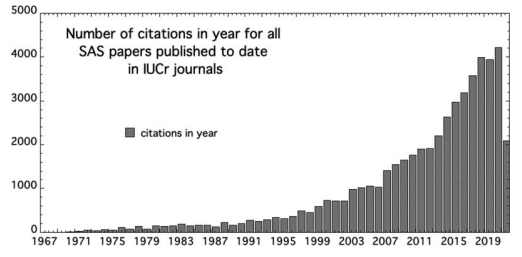

\section{Growing a thriving international community for small-angle scattering through collaboration. Corrigendum}

\author{
Jill Trewhella*
}

School of Life and Environmental Sciences, The University of Sydney, Building G08, Camperdown, NSW 2006, Australia. *Correspondence e-mail: jill.trewhella@sydney.edu.au

Errors in the article by Jill Trewhella [J. Appl. Cryst. (2021), 54, 1029-1033] are corrected.

Table 1 in the article by Trewhella (2021) contains a number of errors. The SAS2009 conference proceedings, including 52 invited and contributed papers, were published in the Journal of Physics - Conference Series, Vol. 247, 2010. The correct numbers of papers and pages for SAS2002 should be 106 papers, 495 pages; for SAS- 99 should be 105 papers, 445 pages; and for SAS- 96 should be 63 papers, 327 pages.

In regard to the origins of canSAS, it was originally an initiative of staff at the Institut Laue-Langevin, European Synchrotron Radiation Facility (ESRF) and ESRF Collaborative Research Groups that came to be taken up by the broader SAS community with support at the SAS conferences.

\section{Acknowledgements}

Thanks to Aldo Craievich and Wim Bras for pointing out these errors.

\section{References}

Trewhella, J. (2021). J. Appl. Cryst. 54, 1029-1033. 